\title{
Evidence of neuroplasticity with robotic hand exoskeleton study for post-stroke rehabilitation: a randomized controlled trial
}

\author{
Neha Singh \\ Indian Institute of Technology Delhi \\ Megha Saini \\ Indian Institute of Technology Delhi
}

\section{Nand Kumar}

All India Institute of Medical Sciences

M.V. Padma Srivastava

All India Institute of Medical Sciences

Amit Mehndiratta ( $\square$ amit.mehndiratta@keble.oxon.org )

Indian Institute of Technology Delhi https://orcid.org/0000-0001-6477-2462

\section{Research}

Keywords: Stroke, Neurological rehabilitation, Wrist, Metacarpophalangeal joint, Robotic exoskeleton, Transcranial Magnetic Stimulation, cortical-excitability

Posted Date: January 22nd, 2021

DOI: https://doi.org/10.21203/rs.3.rs-67841/v3

License: (c) (i) This work is licensed under a Creative Commons Attribution 4.0 International License. Read Full License

Version of Record: A version of this preprint was published at Journal of NeuroEngineering and Rehabilitation on May 6th, 2021. See the published version at https://doi.org/10.1186/s12984-021-00867-7. 


\section{Abstract}

Background: A novel electromechanical robotic-exoskeleton was designed in-house for the rehabilitation of wrist joint and Metacarpophalangeal (MCP) joint.

Objective: The objective was to compare the rehabilitation effectiveness (clinical-scales and neurophysiological measures) of robotic-therapy training sessions with dose-matched Iconventional therapy in patients with stroke.

Methods: A pilot prospective parallel randomized controlled study at clinical-settings was designed with patients with stroke within 2 years of chronicity. Patients were randomly assigned to receive an intervention of 20 sessions of 45 minutes each, five days a week for four weeks, in Robotic-therapy Group (RG) $(n=12)$ and conventional upper-limb rehabilitation in Control-Group (CG) $(n=11)$. We hypothesized to evaluate the exoskeleton based therapy for the effects on the functionality of upper-limb and cortical-excitability in patients with stroke as compared to conventional rehabilitation. Clinical-scales- Modified Ashworth Scale, Active Range of Motion, Barthel Index, Brunnstrom Stage and FuglMeyer scale, and neurophysiological measures of cortical-excitability (using Transcranial Magnetic Stimulation) - Motor Evoked Potential and Resting Motor threshold, were acquired pre and post-therapy. No side effects were noticed in any of the patients.

Results: Both RG and CG showed significant $(p<0.05)$ improvement in all clinical motor-outcomes except Modified Ashworth Scale in CG. RG showed significantly $(\mathrm{p}<0.05)$ higher improvement over CG in Modified Ashworth Scale, Active Range of Motion, and Fugl-Meyer (FM) scale and FM Wrist-/Hand component. An increase in cortical-excitability in ipsilesional-hemisphere was found to be statistically significant $(p<0.05)$ in RG over CG, as indexed by a decrease in Resting Motor Threshold and increase in the amplitude of Motor Evoked Potential. No significant changes were shown by the contralesional-hemisphere. Interhemispheric RMT-asymmetry evidenced significant $(p<0.05)$ changes in RG over CG indicating increased cortical-excitability in ipsilesional-hemisphere along with interhemispheric changes.

Conclusion: Robotic-exoskeleton training appears to be benificial for improving motor-outcomes and cortical-excitability in patients with stroke. Neurophysiological changes in RG could most likely be a consequence of plastic reorganization and use-dependent plasticity.

Trial Registry Number. ISRCTN95291802

\section{Introduction}

Stroke is one of the leading causes of mortality and morbidity worldwide (1). Flexor hypertonia of the wrist is one of the common presentations. The ability to actively initiate extension movements at the wrist and fingers is one of the key indicators of motor recovery (2), (3). Regaining hand function, and activities of daily living (ADL) is particularly impervious to therapy owing to the fine motor control needed for distal-joints (4). Conventional rehabilitation therapy is time-taking, labor-intensive, and subjective. Therapists have a high clinical load and a lack of evidence-based technologies to support them, resulting in therapist burnout and a healthcare system that cannot provide each patient with appropriate and effective rehabilitation services (5).

Although rehabilitation with neuro-rehabilitation robots has shown encouraging clinical results (5-15), it is currently limited to a very few hospitals and not widely used because of associated high-cost and an infrastructural requirement to station these large and complex devices high set-up time and limited usability (16),(17),(18). Rehabilitation-strategies need to take into account the multifaceted nature of the disability, which changes with time and requires a multimodal approach. Hence, the device needs to be flexible enough to accommodate a large patient population. An effective rehabilitation device for the hand should be able to facilitate a specific pattern of coordinated multi-joint movements, which is not integrated into currently available devices.

In our previous work, we have designed a robotic hand exoskeleton for rehabilitation of the wrist and MCP (Metcarpo-phalangeal) joint, to synchronize wrist-extension with finger-flexion and wrist-flexion with finger-extension (19). It is a prototype device with the potential of being a simple and easy to operate exoskeleton rehabilitation device for low-resource settings in the future. The exoskeleton targets spasticity through a synergy based rehabilitation approach while also maintaining patient-initiated therapy through residual muscle-activity for maximizing voluntary effort. The lightweight and portable device has shown evidence of improvement in quantitative motor clinical outcomes in patients with chronic stroke (19).

The aim of the present study was twofold. The first objective was to assess the clinical effectiveness of the novel robotic-exoskeleton device (19) and the second is a comparison of its clinical effectiveness with conventional upper-limb rehabilitation. We hypothesized that the exoskeleton-based rehabilitation therapy might show better clinical outcomes for the distal function of the wrist and cortical-excitability in patients with stroke as compared to conventional-rehabilitation.

\section{Materials And Methods}


More than 300 patients $(n>300)$ were screened in the out-patient clinic of the Department of Neurology, AllMS, New-Delhi over 3 years from July 2016 to January 2019. Stroke diagnosis was established clinically in all patients. All clinical assessments and standard care were given to the patients with stroke by a trained physiotherapist. Institutional Review Board (IRB) at All India Institute of Medical Sciences (AlIMS), NewDelhi, India, approved the study under protocol-number IEC/NP-99/13.03.2015 and was registered with clinical trial number ISRCTN95291802. All the patients signed the written informed consent before enrolment.

\subsection{Study-Design}

A pilot prospective parallel randomized controlled study at clinical-settings was designed which included pre and post-clinical-outcome measures of therapy intervention. Once enrolled, patients were then randomized under two groups- Robotic-therapy group (RG) and ControlGroup (CG). The robotic group received robotic-therapy for 45 minutes of individual sessions for 20 therapy sessions (5 days a week for 4 weeks). The control group received 45 minutes of 20 therapy sessions (5 days a week for 4 weeks) of conventional physiotherapy training. Both the groups continued the care according to the current clinical standards practice in terms of medication as prescribed by the neurologist. The same therapist provided therapy-sessions to all patients in both groups. The person doing the analysis was blinded to the individual data.

\subsection{Patient Enrolment}

Patients were enrolled based on inclusion-criteria, age 18-70 years, having ischemic / hemorrhagic stroke within 3-24 months, Mini-Mental Scale = 24-30; Brunnstrom Stage (BS) = 3-5; Modified Ashworth Scale (MAS) = 1, 1+, 2 (Figure-1). All enrolled patients continued to have their routine medication and standard medical care during the therapy-sessions, as advised by the neurologist. Patients with contraindication to Transcranial Magnetic Stimulation (TMS), no detectable EMG, and any other progressive neurological or cognitive disorders were excluded from the study. The enrolled patients were allocated a predefined allocation sequence. Simple randomization was performed using opaque envelopes within which color cards signified the groups. Patients were instructed to choose the opaque envelopes in the pre-defined sequence. The cards they choose signified the group they were enrolled in for the study. Randomization, outcome measurements, and data analysis were performed by a different individual not involved in the intervention.

\subsection{Data Collection}

All the participants underwent clinical-assessment; a pre-therapy assessment a day before the randomization process and before initiation of robotic or conventional training. The post-therapy assessment was performed a day after the completion of intervention by a trained physiotherapist with more than 5 years of experience.

\subsubsection{Clinical scale measures (primary outcomes)}

The primary outcomes were the level of spasticity at wrist joint by Modified Ashworth Scale (MAS: 0-4), range of voluntary wrist movement defined in terms of Active Range of motion of wrist (AROM: $0^{0}-70^{0}$ ) as measured by a goniometer, stage of stroke recovery Brunnstrom Stages (BS: 1-7), Barthel-Index (BI: 0-100) and functional and sensorimotor-control of upper-limb as measured by upper-limb Fugl-Meyer Scale (FM: 0-66) (Figure 1).

\subsubsection{Cortical-excitability measures using TMS (secondary outcomes)}

Patients were allowed to sit comfortably in the chair, kept forearm pronated, elbow-joint at $90-120^{\circ}$ flexion, wrist-joint at a neutral position, and fingers at rest. Single-pulse TMS at 100\% Motor Threshold was given to all the patients to evoke the Motor Evoked Potential (MEP) signal, using a flat 70mm figure of eight coil (type D70 (AC), serial no. 0326, Magstim Rapid², Magstim, UK), at the cortical representation of the Extensor Digitorum Communis (EDC) muscle (on contralateral motor-cortex with reference to the EEG cap) of the ipsilesional and contralesional-hemisphere. Cortical-excitability was measured in terms of Resting Motor Threshold (RMT) and Motor Evoked Potential (MEP) amplitude using TMS over ipsilesional and contralesional-hemisphere according to the standard protocol (20). RMT was defined as the minimum intensity of TMS required to elicit an MEP in target contralateral-muscle in 5/10 trials, recorded in EMG, over the muscle cortical representation in the primary motor cortex. MEP encapsulates information relevant to the cortical-excitability of the brain, conduction and functional-integrity of the corticospinal-tract (21). MEP should be $\geq 50 \mu v$ peak-to-peak amplitude at the hotspot in $5 / 10$ consecutive trials. Five MEP signals out of 10 consecutive trials were averaged.

\subsection{Robotic therapy-sessions}

An electromechanical robotic-exoskeleton was developed for rehabilitation of wrist-joint and fingers-joint (Figure-2) (19). Stages of motion sequence were: wrist at the neutral position, finger extension (baseline position) à wrist extension finger flexion (final position) à back to wrist flexion, finger extension (towards baseline position); with constant speed (28 degrees/second) for all patients. The device was user-friendly 
and patient-centric as per the clinical-presentation: with customizable motion-parameters, (i) initial position for a range of motion (ROM), (ii) final position for ROM, (iii) speed, (iv) residual muscle-activity and (v) height of finger-support. All sessions were given at the hospital set-up under the supervision of an expert clinician. Each 45 minutes robotic-therapy session consisted of approximately 250 trials of 10 seconds each, excluding the set-up time, breaks, donning, and doffing of the exoskeleton or consultation which was an additional 10-15 minutes. Patients were advised to take 5 minutes break for rest in between the therapy if there is a feeling of pain or fatigue, this time was then added to the total therapy time, keeping the active therapy session to 45 minutes consistently.

The device is actively initiated by Electromyogram (EMG) activity of Extensor Digitorum Communis (EDC) muscle with robot motion-triggered only if the EMG thresholds (set with the consensus of the therapist at the time of first therapy sitting) are crossed and it provides an interactive adaptive performance visual biofeedback in real-time (19). At baseline position, the patient tries to extend the wrist voluntarily for the first three seconds after the green LED cue. If the EMG crosses the predefined threshold, the exoskeleton will be triggered for an assisted wrist extension and finger flexion movement. Once it reaches the final position, the exoskeleton then assists the patient's hand back to the baseline position, wrist flexion with finger extension. Simultaneous to this motion assistance, the performance feedback is given to the patient in realtime. To ensure each cycle lasted $10 \mathrm{sec}$, a delay of a few sec/milliseconds (depending on the individual patient's completion time) was provided after the completion of each cycle (19). If the EMG threshold is not crossed, the exoskeleton will not assist the movement and the trial cycle is reset to begin again for the patient to try harder with the repeated three seconds voluntary cue (19). The configurability of the threshold was adjusted during the study manually and individually using the BIOPAC MP150 EMG acquisition software according to the residual EMG activity of an individual patient with an advantage of making the system patient-specific and including patients with minimal residual muscle activity in the protocol. At pre-therapy amplitude of the threshold was in the range of $0.101 \pm 41.74 \mathrm{~V}$ (amplified with gain $=$ 2000, Band Pass Filter $=10-500 \mathrm{~Hz}$, Notch Filter $=50 \mathrm{~Hz}$, Sampling Frequency $=1000 \mathrm{~Hz}$ ) for our patient cohort. The final range of motion was incremented during the intervention according to the comfort of the patient. For further details on the device, please refer to our previous work Singh et al. (19).

\subsection{Conventional therapy-sessions}

The conventional therapy session was conducted for 45 min per day for 5 days a week for 4 weeks. The type of activity, intensity, and frequency was based on the baseline clinical presentation of the patient as reflected by clinical scales (MAS, FMA, BI, Brunnstrom Stage, and Range of motion). More details on the therapy protocol are presented in the supplementary material.

\subsection{Data analysis}

Data analysis was performed in MATLAB R2018a (MATHWORKS $®$ ). The data were tested for normality using the Shapiro-Wilk test and was found that clinical measures were not normally distributed in CG. Hence, non-parametric Wilcoxon signed-rank were used for intragroupcomparison of differences in the post-pre-therapy within the group, and non-parametric Mann-Whitney tests were used for intergroupcomparison of RG and CG. Interhemispheric-asymmetry for pre-and post-therapy measures were calculated and was tested using the Wilcoxon signed-rank test. Two-way repeated measure ANOVA was applied to assess the effect of time (two levels-pre and post) and side (two levels-ipsilesional and contralesional) on RMT. Regression and correlation-analyses were performed to investigate the relationship of recovery parameters TMS neurophysiological parameters with clinical-outcome. A p-value < 0.05 was considered statistically significant. MAS score of $1,1+, 2,3$, 4 was mapped as 1, 1.5, 2, 3, 4 for all statistical calculation purposes, respectively as suggested by Rong et. al (14).

\section{Results}

Twenty-seven patients who met the eligibility criteria were randomized and allocated into two groups- RG ( $n=13)$ and CG ( $n=14)$. One patient $(n=1)$ in RG and three patients $(n=3)$ in CG could not complete the therapy due to their non-availability, thus, the data were excluded from further analysis. All patients in RG ( $n=12)$ and CG ( $n=11)$ (all right-handed patients with stroke, age=41.9 \pm 11.1 years, Male:Female=19:4) (Table-1) completed successfully the therapy-sessions in 30-34 days. The CG $(n=11)$ included patients with stroke, lesion locations with subcortical in five $(n=5)$ and cortical in six $(n=6)$ patients. RG $(n=12)$ included patients with stroke, lesion locations with sub-cortical in six ( $n=6)$ and cortical in six $(n=6)$ patients. The volume of the lesion was $15.98 \pm 23.6 \mathrm{~cm}^{3}$ in $C G$ and $25.37 \pm 45.48 \mathrm{~cm}^{3}$ in $R G$. There were no significant $(p>0.05)$ differences in the pre-therapy measures in terms of clinical-scales and lesion volume among both the intervention-groups (table-1). At pre-therapy measurements, MEP was evoked only for 9 patients $(R G=4, C G=5)$ out of a total of 23 in ipsilesional-hemisphere, and for all patients in contralesional-hemisphere. The thresholds for the triggering of the exoskeleton changed from $0.101 \pm 41.74 \mathrm{~V}$ at day 1 to $0.383 \pm 171 \mathrm{~V}$ at day 20 for our patients' cohort with a relative increase by $\sim 3$ times. No side effects or adverse effects were noticed in any of the patients. 
Table 1: Details of patients with stroke enrolled in Robotic Group and Control Group

\begin{tabular}{|llll|}
\hline Measures & $\begin{array}{l}\text { Pre-Therapy measures Robotic Group }(\mathbf{n}=12) \\
\text { Mean } \pm \text { SD }\end{array}$ & $\begin{array}{l}\text { Pre-Therapy measures Control Group }(\mathbf{n}=11) \\
\text { Mean } \pm \text { SD }\end{array}$ & p-value \\
\hline Age & $41.1 \pm 12.8$ & $42.7 \pm 9.3$ & 0.75 \\
\hline Chronicity & $13.8 \pm 9.1$ & $10.3 \pm 5.0$ & 0.47 \\
\hline MAS & $1.75 \pm 0.2$ & $1.86 \pm 0.5$ & 0.46 \\
\hline AROM & $15.0 \pm 9.7$ & $13.6 \pm 7.7$ & 0.34 \\
\hline BI & $74.1 \pm 12.4$ & $69.5 \pm 12.9$ & 0.41 \\
\hline BS & $3.67 \pm 0.7$ & $3.72 \pm 1$ & 0.9 \\
\hline FMU/L & $36 \pm 7.7$ & $37.45 \pm 9.1$ & 0.98 \\
\hline FMW/H & $9.7 \pm 2.7$ & $11.45 \pm 2.9$ & 0.27 \\
\hline FMS/E & $26.2 \pm 5.6$ & $26 \pm 7.07$ & 0.78 \\
\hline Lesion Volume $\left(\mathrm{cm}^{3}\right)$ & $25.3 \pm 45.48$ & $15.9 \pm 23.6$ & 0.47 \\
\hline
\end{tabular}

\subsection{Comparison of Clinical-scales}

Post-therapy, all clinical-scales in both groups did show significant changes in improvement, except for MAS in CG. However, all clinical-scales (MAS, AROM, FM, and FMW/H) in RG showed statistically significant changes compared to the CG. MAS in RG decreased from $1.75 \pm 0.2$ to $1.29 \pm 0.3$ and in $C G$ from $1.86 \pm 0.5$ to $1.59 \pm 0.6$ showing a significant decrease in spasticity at wrist-joint in $R G$ and not in $C G$ (RG $p=0.0009, C G$ $p=0.12$ ) with significant ( $p=0.03$ ) intergroup changes (Table-2). AROM and BI, in both the groups, showed statistically significant differences. AROM significantly increased in both the groups, from $15.0^{0} \pm 9.7^{0}$ to $34.6^{0} \pm 14.5^{0}$ in $R G(p=0.0004)$ and from $13.6^{0} \pm 7.7^{0}$ to $20.0^{0} \pm 8.1^{0}$ in $C G$ $(p=0.002)$. However, RG manifested statistically significant AROM scores as compared to CG as intergroup comparison did evidence significant differences ( $p=0.02)$ (Table-2). BI increased from 74.1 \pm 12.4 to 89.1 \pm 7.9 in $R G(p=0.0009)$ and from $69.5 \pm 12.9$ to $82.7 \pm 14.3$ in $C G$ $(p=0.0009)$; the intergroup comparison did not show any significant differences $(p=0.82)$. BS showed statistically significant differences in both groups, RG increased from 3.6 \pm 0.7 to $4.8 \pm 0.9(p=0.0004)$ and CG changed from $3.7 \pm 1$ to $4.4 \pm 1.2(p=0.015)$. The intergroup comparison did not show significant differences between both groups $(p=0.311)($ Table-2).

FMU/L scores measure sensorimotor control gain in both groups. FMU/L for RG increased from $36 \pm 7.7$ to $50.2 \pm 6.5$ ( $p=0.0004)$ and from $37.4 \pm 9.1$ to $45.4 \pm 9.7$ for CG ( $p=0.0009)$. RG manifested statistically significant improvement in sensorimotor scores as compared to $C G$ with significant $(\mathrm{p}=0.039)$ differences in intergroup comparison (Table-2). For the proximal part -Shoulder/Elbow component of FMS/E, both groups showed a statistically significant increase, RG changing from $26.2 \pm 5.6$ to $33.5 \pm 3.8$ ( $p=0.0009$ ) and from $26 \pm 7.07$ to $29.8 \pm 7.08$ in $C G$ $(p=0.002)$. However, the intergroup-comparison did not show any significant $(p=0.13)$ differences. For the distal part Wrist/Hand component of FM (FMW/H), both groups showed a statistically significant increase, in RG changing from 9.7 \pm 2.7 to $16.6 \pm 4.3$ ( $p=0.0004)$ and in $C G$ changing from $11.4 \pm 2.9$ to $15.1 \pm 3.6(p=0.0009)$. RG manifested statistically significant $(p=0.012)$ sensorimotor improvement in intergroup comparison over CG (Table-2).

Table 2: Comparison of clinical-scales, cortical-excitability (in ipsilesional and contralateral-hemisphere) and interhemispheric parameters in Robotic Group with Control Group 


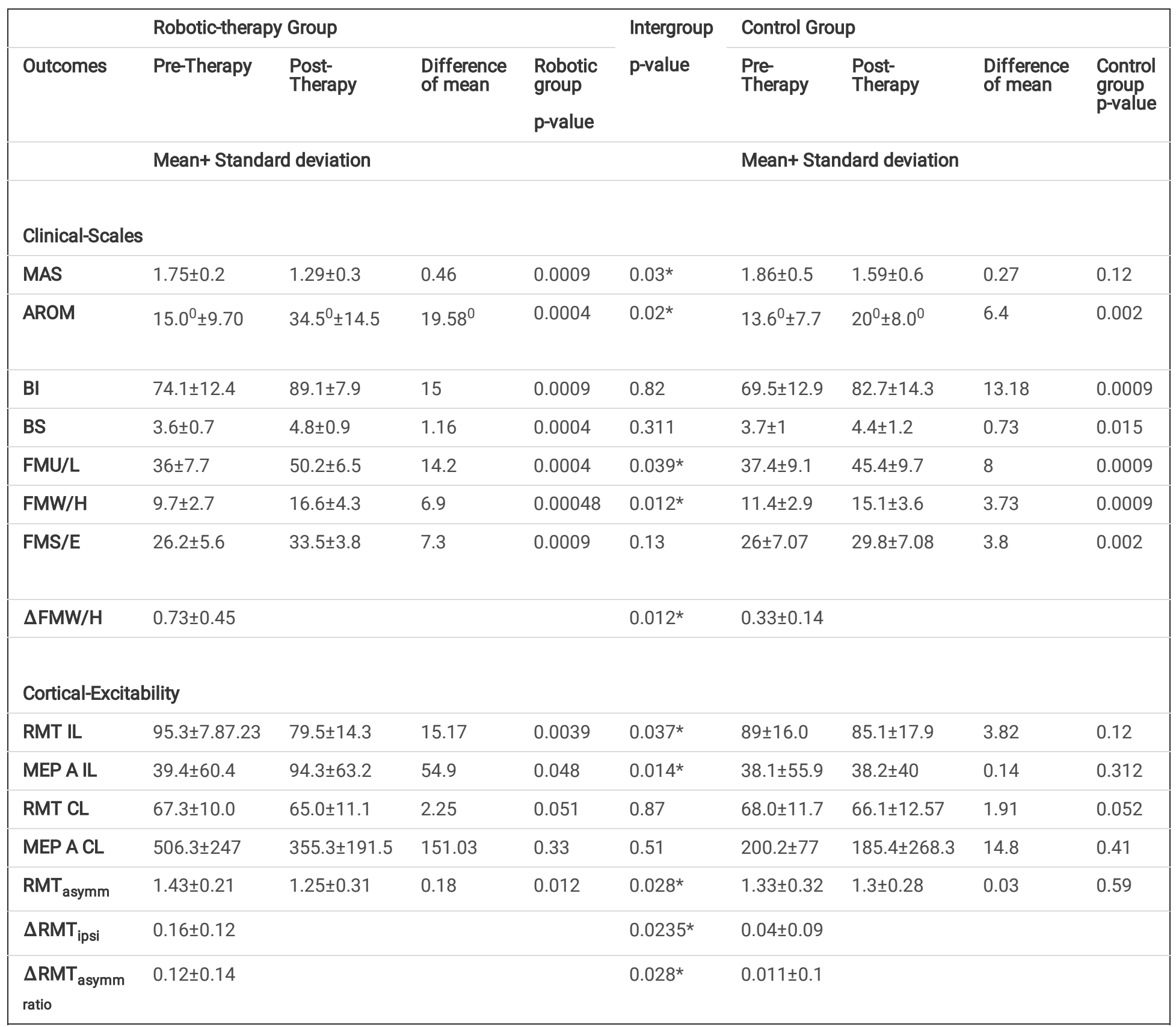

\section{*shows the statistical significance differences $(p<0.05)$ between RG and CG}

MAS (max 4) : Modified Ashworth Scale

BI (max 100): Barthel Index

FMU/L (max 66): Fugl-Meyer Upper Limb Scale

FMS/E (max 42): Fugl-Meyer Shoulder Elbow

IL: Ipsilateral, CL: Contralateral
AROM (max 70): Active Range of Motion

BS (max 7): Brunstrom Stage

FMW/H (max 24): Fugl-Meyer Wrist Hand

MEP A( $\mu v)$ : MEP Amplitude RMT (\%)

$\mathrm{RMT}_{\text {asymm }}=(\mathrm{RMT}$ Ipsilesional / RMT contralesional),

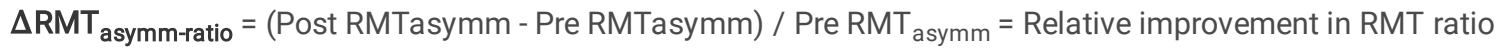

$\Delta \mathrm{RMT}_{\text {ipsi }}=\left(\right.$ Pre RMT $_{\text {Ipsi }}-$ Post RMT $\left._{\text {Ipsi }}\right) /$ Pre RMT $_{\text {Ipsi, }}($ RMT decreases in case of improvement $)=$ Relative decrease/improvement in ipsilesional RMT

$\Delta \mathrm{FMW} / \mathrm{H}=($ Post FMW/H - Pre FMW/H)/ Pre FMW/H = Relative improvement in Fugl-Meyer $(\mathrm{W} / \mathrm{H})$ 


\subsubsection{Ipsilesional-hemisphere}

MEP, in some patients with stroke, is not recordable even after delivering TMS-stimuli at the highest possible stimulation intensity, possibly due to decreased cortical-excitability in stroke as also reported by (22-26). In those patients with no MEP recorded, RMT is taken as a value of 100 , as has been suggested in the literature (27)(28). For healthy subjects, MEP ranges $186.4 \pm 88 \mu$ v at $55 \pm 10$ stimulation intensity at $100 \%$ RMT (21). Change in RMT showed statistically significant differences in post-therapy in RG as compared to CG. Post-therapy, RG showed a significant decrease in RMT from 95.3 \pm 7.87 .23 to 79.5 $\pm 14.3(p=0.0039)$, whereas CG showed a decrease from 89 to $85.1 \pm 17.9$ ( $p=0.12$ ) (Table-2). RG also evidenced a significant increase in MEP amplitude from 39.4 $\pm 60.4 \mu \mathrm{v}$ to $94.3 \pm 63.2 \mu \mathrm{v}$ ( $p=0.048$ ). In CG, MEP almost remained the same $(\sim 38 \mu v)$ pre to post-therapy $(p=0.312)$. A decrease in RMT $(p=0.037)$ and increase in MEP amplitude $(p=0.0142)$ was seen in RG as compared to CG (Table-2).

In this study, $54 \%$ of patients in CG did not evoke MEP at the pre-therapy measurement. $67 \%$ of patients in RG too did not evoke MEP at the pre-therapy measurements. In CG, MEP was evoked only in 5/11 patients at the pre-therapy measurements and was observed in $6 / 11$ patients post-therapy. However, it is worth noting that in RG, measurable MEP was evoked only in 4/12 patients at the pre-therapy measurements, and post-therapy MEP was observed in 9/12 patients, thus, 5 additional patients showing MEP after robotic therapy intervention. These five additional patients having no MEP amplitude at 100\% stimulation intensity in pre-therapy, were observed to have MEP amplitude of $136.6 \pm 38.4 \mu \mathrm{v}$ in post-therapy at $73.0 \pm 9.64 \%$ stimulation intensity. For these five patients, an increase in clinical scales was also observed as; FMW/H increase from $8.2 \pm 2.4$ to $16.0 \pm 4.1$ (an absolute increase of $7.8 \pm 2.3$ ), Bl from $70.0 \pm 11.7$ to $92.0 \pm 8.3$ (an absolute increase of $22 \pm 11.7$ ) and AROM from $15.0^{0} \pm 5.0^{0}$ to $37.0^{0} \pm 2.7^{0}$ (an absolute increase of $22^{0} \pm 2.7^{0}$ ) in RG.

\subsubsection{Contralesional-hemisphere}

There were no significant changes shown in the contralesional-hemisphere. Both RG and CG evidenced minimal differences in RMT (mean increase of $\sim 2 \%$ in both groups) (Table-2). RG showed decrease from $67.3 \pm 10.07$ to $65.08 \pm 11.12$ ( $p=0.051)$ and CG from $68.09 \pm 11.7$ to $66.1 \pm 12.5$ ( $p=0.052$ ). Intergroup-comparison too did not show statistically significant differences ( $p=0.87)$ (Table-2). MEP amplitude in RG decreased from $506.3 \pm 247$ to $355.3 \pm 191.5 \mu v(p=0.33)$ and from $200.2 \pm 77 \mu v$ to $185.4 \pm 268.3 \mu v$ in CG ( $p=0.41)$. MEP amplitude observed a considerably higher decrease (mean 151 $\mu \mathrm{v}$ ) in RG, as compared to CG (mean 15 $\mu \mathrm{v}$ ). The intergroup comparison, however, was not statistically significant $(p=0.51)$ between both the groups (Table-2).

\subsubsection{Interhemispheric differences and asymmetries}

The effect of robotic-exoskeleton training on cortical-excitability was assessed within both hemispheres. RG showed statistically significant differences between ipsilesional and contralesional sides as one factor and time points- pre and post-therapy as another factor on RMT $(p=0.049, F=4.08)$, evidencing the dependence of time and hemisphere sides on each other. However, CG did not show any statistical differences $(p=0.06, F=3.68)$.

RG also evidenced a statistically significant reduction in interhemispheric-RMT asymmetry as measured by the ratio of RMT for two hemispheres $\left(\mathrm{RMT}_{\text {asymm }}=\mathrm{RMT}\right.$ Ipsilesional / RMT contralesional) from pre to post-therapy (Table-2). RG showed a decrease in RMT from $1.43 \pm 0.21$ to $1.25 \pm 0.31$ (mean decrease of $0.18, p=0.012$ ), whereas, CG showed a decrease from $1.33 \pm 0.30$ to $1.30 \pm 0.28$ (mean decrease of $0.03, p=0.59$ ), indicating a trend of normalization of RMT-asymmetry (RMT asymm should decrease as ipsilesional RMT should be decreased from the pre to post) over the course of intervention in RG. RG also manifested statistically significant $(p=0.028)$ changes in intergroupcomparison over CG (Table-2). The relative change in interhemispheric-RMT asymmetry-ratio $\left(\Delta \mathrm{RMT}_{\text {asymm-ratio }}\right)$ changed with RG having a mean increase of $0.12 \pm 0.14$ and CG a mean increase of $0.011 \pm 0.1(p=0.028)$, indicating the higher extent of normalization of RMT-asymmetry over the duration of intervention in RG as compared to CG (Table-2).

\subsection{Relationship between TMS neurophysiological measures and clinical-outcome}

The recovery parameters from TMS measures denoting the change from pre- to post-therapy were observed to be correlated with the relative change/improvement in distal motor-outcome $(\Delta \mathrm{FMW} / \mathrm{H})$. The first parameter, the relative change in RMT in the ipsilesional-hemisphere $\left(\Delta \mathrm{RMT}_{\mathrm{ipsi}}\right)$ was significantly $(\mathrm{p}=0.0235)$ different for both the groups with a mean increase of $0.16 \pm 0.12$ in $\mathrm{RG}$ and $0.04 \pm 0.09$ in $\mathrm{CG}$. The linear regression analysis indicated that $\Delta \mathrm{RMT}_{\mathrm{ipsi}}$ (as a predictive or independent variable) could correlate with $\Delta \mathrm{FMW} / \mathrm{H}$ (as a dependent variable) and could predict $\Delta \mathrm{FMW} / \mathrm{H}$ in $\mathrm{RG}(\mathrm{r}=0.64, \mathrm{~F}=7.24, \mathrm{p}=0.022)$ (Figure-3a), indicating that can be correlated with the functional clinical-

outcome. This correlation was not found in $\mathrm{CG}(\mathrm{r}=0.47, \mathrm{~F}=2.62, \mathrm{p}=0.13)($ Table-2, Figure-3a). The relationship between $\Delta \mathrm{RMT}$ ipsi and $\Delta \mathrm{FMW} / \mathrm{H}$ for both groups is shown in the scatter-plot in figure-3a. The distal functional outcome $\Delta \mathrm{FMW} / \mathrm{H}$ also showed significantly ( $\mathrm{p}=0.012$ ) different results for both groups with a mean increase of $0.73 \pm 0.45$ in RG and $0.33 \pm 0.14$ in CG.

Page $7 / 17$ 
The second parameter, the relative change in RMT-ratio $(\Delta \mathrm{RMT}$ asymm-ratio $)$ was significantly $(\mathrm{p}=0.028)$ different for both the groups. Similar to above, $\Delta \mathrm{RMT}_{\text {asymm-ratio }}$ (as predictive/independent variable) was observed to be correlated $\Delta \mathrm{FMW} / \mathrm{H}$ (as a dependent variable) $(\mathrm{r}=0.6, \mathrm{~F}=5.77$, $p=0.03$ ) (Figure-3b), indicating that tendency towards the extent of normalization RG could be correlated and used further for predictive the clinical-outcome in RG. This correlation was not found in $\mathrm{CG}(\mathrm{r}=0.29, \mathrm{~F}=0.83, \mathrm{p}=0.38)$ (Figure-3b). The relationship between $\Delta \mathrm{RMT}$ asymm-ratio and $\Delta \mathrm{FMW} / \mathrm{H}$ in both groups is shown in the scatter-plot in figure-3b.

\section{Discussion}

The study demonstrated clinical and neurophysiological changes in response to the robotic-exoskeleton (19) training compared to the conventional-rehabilitation. Clinical-scales showed improvement in both RG and CG, however, increased cortical-excitability in the ipsilesionalhemisphere was shown only in RG with the appearance of MEPs in the ipsilesional-hemisphere post-therapy in patients. The improvement in RMT in the ipsilesional-hemisphere showed a trend of normalization over the intervention and was also correlated with sensorimotor function improvement.

\subsection{Comparison of Clinical-scales of Robotic-therapy group with control-group}

The robotic-therapy was effective in releasing spasticity at the wrist joint with $\sim 26 \%(p=0.03)$ improvement over only $\sim 14 \%$ in CG. The regain in normal muscle tone is considered as a predictor of recovery or the first step in recovery (29) followed by an increase in muscle strength and improvement in functional movements. Both groups showed significant improvement of AROM, RG showed significantly ( $p=0.02$ ) higher improvement of $130 \%$ over $47 \%$ in CG (Table- 2 ).

FMU/L, stroke-specific scale, is the most reliable measure of sensorimotor functionalities of the whole arm (30). RG established significantly higher improvements in FMU/L of $\sim 40 \%$ over $21 \%$ in CG $(p=0.039)$. For FMW/H distal-component, both groups showed significant improvement, where RG showed significantly higher improvement of $72 \%$ compared to only $32 \%$ in CG ( $p=0.012$ ) possibly because of intensive and repetitive training of wrist and MCP. However, RG did not show significantly higher improvement in FMS/E, as expected as the intervention was not focused on the proximal component. With contemporary studies showing improvements even in the proximal component in response to distal training, our study too reflected change in proximal joint (FMS/E) post-therapy, probably because of the compensatory muscle activities from proximal-joints (13)(31).

Thus, RG shows an overall increase in sensorimotor ability and functionality as evidenced by the increase in FM, AROM and decrease in spasticity (MAS); thereby, attributing to increased mobility and stability of wrist extension and hand activities like grasping, which in turn, reflected improvements in FMW/H scores. As shown in the studies by Gladstone et al., and Shin et al., (32)(33), a value of 6.6 (FMU/L) reflects the potential Minimally Clinically Important Difference (MCID). In our study, FMU/L (14 on a scale of 66) was found to be higher than the MCID values for all 12 patients in RG and 7/11 patients in CG. The Hand Mentor Pro, which rotates wrist with MCP placed at a constant angle with respect to the wrist, lacks flexion (grasp) and extension (release) of MCP, patient-centric ROM and speed, reported improvement in 99 patients with stroke with FMW/H being 5.6 (FMU/L 10.33 in combination with a home exercise program (which alone reported FMW/H 4.9 and FMU/L 9.3). The HWARD (31) also showed an improvement in FMW/H ( 4) with sensorimotor cortex laterality index representing a shift in interhemispheric balance over time from the contralateral to ipsilateral side and also suggested the use of synchronizing both wrist and MCP-joint movement in grasp and release.

With Constraint-Induced Movement therapy (CIMT), the reported gain was FMU/L 13 and BI 13.5, post 3 weeks therapy (34). Moreover, a systematic review and meta-analysis has shown improvement in FMU/L scores Action Research Arm Test (ARAT) scores with an improved control of hand and arm placement as well as improved strength compared to standard therapy post-CIMT in the subacute and chronic stroke populations (35). Few studies have also shown significant increased motor map area via TMS post-CIMT (3)(36). Sawaki et al., showed increased in the TMS motor map area (of EDC muscle in ipsilesion hemisphere in few patients) and clinically relevant improvements in arm motor function that persisted for at least 4 months, however, other TMS parameters like Resting Motor Threshold, Active Motor Threshold, Center of Gravity, silent period did not change over time (37). Use of biofeedback has been another widely explored area, where Doan-Aslan et al. and Zheng et al. has demonstrated an increase in AROM, BI and FMU/L in patients with stroke while using EMG Biofeedback compared to the conventional therapy (38)(39). In our study, an improvement in FMW/H by 3 was observed with intervention therapy compared to the CG, which is consistent with the literarure. Krishnan et al. and Calabrò et al. have attempted to evaluate the effect of active robotic-training on changes in cortical-excitability, using commercially available devices, such as Lokomat robot (lower-limb) (40) and ARMEO (upper-limb) (41). With very sparse literature exploring cortical excitability changes in lower-limb (42) and upper-limb (43), virtual mirror task with feedback demonstrated increased MEP by up to $46.3 \%$ (95\% Cl: 30.4 80.0) compared with the real mirror task (43).

For the Barthel Index, both groups showed similar ( 20\%) improvement ( $p=0.82)$. Both groups showed significant improvement for BS as well, however, RG showed 32\% improvements compared to only 20\% in CG (Table-2). In the case of the Barthel Index and Brunnstrom Stage, 
both RG and CG showed a similar improvement as the rehabilitation regimen in the CG group incorporated clinical rehabilitation with a primary focus on the upper extremity deficits with the therapist focusing on the distal limb and overall recovery along with customizing the patient's goals directly and training compensatory and functional movement strategies that consequently resulted in equal gains in independence and patients' goals as in RG. Also, in the future, substantial consideration can be given to Barthel Index scores by introducing kinematic analysis of speed, accuracy, and precision of movement and BI-based patient perception scales like self-perceived difficulty scale and ability scale for better quantitative measurement.

\subsection{Comparison of Cortical-excitability of Robotic-therapy with the control-group}

Cortical-excitability in pre-therapy measurements was found to be lower in patients with stroke as observed by higher RMT and lower MEP, same as reported in (22-26). In some patients due to low cortical-excitability, MEP is not recordable even after delivering TMS stimuli at the highest possible intensity at $100 \%(22-26)$. In those patients with no MEP recorded, RMT is taken as a value of 100 , as suggested in the literature $(27,28)$. Though a subset of patients with stroke with affected corticospinal tract integrity that does not demonstrate MEP with the highest stimulation intensity, taking RMT as 100\% could affect the decrease in RMT post-therapy in the RG group. However, critical studies like Hendrics et al., and Jong et al., have established MEP as a sensitive and valid prognostic marker of motor recovery after stroke (44-46).

\subsubsection{Ipsilesional and Contralesional-hemisphere changes}

With the decrease in RMT, RG showed $~ 16 \%$ improvement as compared to $~ 4 \%$ improvement in CG ( $p=0.037$ ). Interestingly, RG showed a significantly ( $p=0.048)$ higher increase in MEP-amplitude post-therapy with an increase of 140\% (mean=54.9 $\mu \mathrm{v})$, whereas CG showed no such improvement. Cortical-excitability measures are used as an objective investigative tool to measure the treatment responsiveness and prognostication as it provides insights into membrane-excitability of neurons, conduction, and functional integrity of the corticospinal tract and neuromuscular-junctions (47). A decrease in RMT and increase in MEP amplitude in the ipsilesional- hemisphere, demonstrated in the RG and not in CG, might be related to the increase in cortical-excitability (48). It might be interpreted that recovery of motor function could most likely be a consequence of plastic reorganization and use-dependent plasticity (48). Cortical-excitability and corticospinal tract integrity have also been shown to be correlated with functional recovery potential in patients with chronic stroke (23) and exoskeleton training appears to be beneficial in activating the ipsilesional-hemisphere for our patient cohort (chronicity $13.8 \pm 9.1$ months). Activation of ipsilesional-hemisphere could indicate either vicariation of the loss of neural circuits or unmasking of preexisting synapses or recruitment of perilesional areas in ipsilesional-hemisphere or exploitation of the preserved functional recovery reservoir in ipsilesional-hemisphere (27,49-51).

In the contralesional-hemisphere, MEP-amplitude showed a considerable decrease in both groups, though not significant, RG evidencing a decrease of $\sim 30 \%$ (mean=151.03 $\mu \mathrm{v}$ ) and CG a decrease of only $\sim 7 \%$ (mean=14.8 $\mu \mathrm{v}$ ) with no significant differences ( $p=0.51)$ (Table-2). A $\sim 30 \%$ decrease in MEP-amplitude in contralesional-hemisphere over the duration of intervention might represent a decrease in corticalexcitability (49)(50), however, is difficult to comment on it at this stage due to the small sample size and needs to be further evaluated in a larger cohort.

The potential clinical effectiveness harnessed by the neuro-rehabilitation robots has also been shown by few studies in terms of subjective clinical scales or questionnaires or EMG parameters which might not be sufficient to assess cortical reorganization (9)(11)(7,13-15)(52-56). However, the mechanism of entrainment of neuroplasticity followed by a stroke that favors motor learning and functional recovery is still unclear (57). Despite recognizing that the corticospinal tract plays a critical role in recovery potential, cortical reorganization, functional improvement in stroke, and as well as better track clinical progression, the changes in these measures evaluating effects due to intervention are usually limited to the studies involving brain stimulation protocols. Examples are repetitive TMS, Transcranial Direct Current Stimulation (tDCS) (58),(59), etc. or in a combination of brain-stimulation with other neuro-rehabilitation strategies like CIMT (60) or mirror-therapy (61) or training (62),(63). Hence, only limited studies are available assessing for these measures unveiling objective changes using robotic-therapy as a rehabilitation intervention (58-66).

Though the study using the device HWARD provided seminal evidence of reorganization of brain (via fMRI), as well as motor function in response to the robotic-therapy, no direct comparison can be made with our study as different modalities - TMS and fMRI was used to measure different neurophysiological aspects (31). Juan et al., correlated results by these modalities and presented that larger fMRI activation likelihood and motor cortical excitability in the ipsilesional primary motor area were related to improved motor performance (67).

\subsubsection{Specific five-patients in $R G$}

A very critical outcome of the therapy was that in RG, MEP was evoked in ipsilesional-hemisphere only for 4/12 patients at the pre-therapy measurements; whereas, MEP was later evoked for $9 / 12$ patients after robotic-therapy. However, in CG, MEP was evoked only for $5 / 11$ patients and was later evoked for $6 / 11$ patients at post-therapy. Considering these five specific patients in RG who did not evoke MEP at pre-therapy and later evoked MEP (mean=136.6 $\pm 38.4 \mu \mathrm{v}$ ), with a decrease of stimulation intensity in ipsilesional-hemisphere by almost $27 \%$ and

Page 9/17 
substantial improvement in the value of clinical-scales (FMW/H by $7.8 \pm 2.38$, BI by $22 \pm 11.72, A R O M$ by $22^{0} \pm 2.73^{0}$ ). These changes were relatively much higher than the changes in patients who had MEP evoked at pre-therapy measures. The appearance of MEP in five patients after 4 weeks of robotic intervention is a crucial outcome and represents that the robotic-therapy might have the potential of facilitating clinically relevant reorganization of the brain-based on use-dependent plasticity. The observed increase in cortical-excitability and normalization of TMS neurophysiological makers on the ipsilesional-side was also observed to be accompanied by recovery of hand-function, as observed by sensorimotor and functional recovery (by clinical-scales FMW/H, BI \& AROM).

\subsubsection{Inter-hemispheric differences and asymmetries}

The diaschisis between ipsilesional-areas and intact neuronal-networks of contralesional-areas may disturb the cortical-excitability and connectivity patterns of connected, remote, or primary-motor areas of contralesional-hemisphere (via transcallosal-fibers). The effect of robotic-exoskeleton training on cortical-excitability of both hemispheres might be attributed to remodeling of the bilateral primary-motor areas in $R G$ (time* sides $p=0.049, F=4.08$ ) which is not shown in $C G$ (time* sides $p=0.06, F=3.68$ ).

For cortical excitability to be increased in ipsilesional-hemisphere for patients with stroke, the ipsilesional-RMT should be decreased from preto-post-therapy and hence, RMT asymm (RMT Ipsilesional/RMT contralesional) should decrease to approach normalization (27). Significant differences were observed between the groups when TMS-neurophysiological changes over the intervention were expressed in terms of the interhemispheric-asymmetry ratio RMT asymm might be a representative of a trend $(\mathrm{p}=0.028)$ towards the normalization of asymmetry of $\mathrm{TMS}$ measures in RG in response to exoskeleton-training than CG. Normalization might indicate the recruitment of peri-lesional areas in the ipsilesional-hemisphere or exploitation of the preserved functional-recovery reservoir in the ipsilesional-hemisphere (27,49-51).

\subsection{TMS neurophysiological improvement correlating the motor-outcome of both groups}

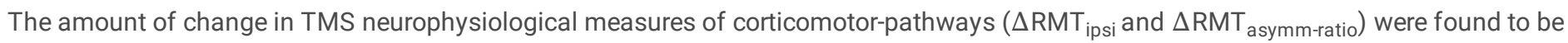
associated with the amount of improvement in functional motor-outcome during the rehabilitation of the distal-part of the upper-limb $(\Delta F M W / H)\left(\right.$ Figure-3). These parameters were significantly different for $R G$ and $C G\left(\Delta R M T_{i p s i} p=0.0235, \Delta R M T\right.$ asymm-ratio $p=0.028$ and $\Delta \mathrm{FMW} / \mathrm{H} \mathrm{p}=0.012$ ). An improvement (decrease) in motor-threshold tend to show greater increases with clinical-outcome and was found to have positive correlation with $\Delta F M W / H$ in $R G\left(\Delta R M T_{i p s i} r=0.64, p=0.022\right)$ and not in $(C G r=0.47, p=0.13)$ and $\Delta R M T$ asymm-ratio $(r=0.6, p=0.03)$ and not in CG ( $r=0.29, p=0.38)$ (Figure-3). The improvement (decrease) in RMT, could be associated with recovery of motor function as suggested by (23). This might be most likely due to increased cortical-excitability of preserved motor-pathways as shown in earlier studies in sub-acute and chronic stroke, demonstrating the correlation of improvement in TMS neurophysiological measures with functional improvement (27), (68), (69). These neurophysiological-measures were obtained specifically from the cortical representation of EDC muscle, a clinically affected muscle, with a specific function which was involved in training with a robotic-exoskeleton, whereas, most clinical measures do not necessarily require a particular muscle group and measures motor-function in a broader sense.

Also, these neurophysiological-parameters individually establishes as a good predictor of functional rehabilitation-outcome of hand $(\Delta \mathrm{FMW} / \mathrm{H})$ in $\mathrm{RG}$, indicating that changes in cortical-excitability of ipsilesional-hemisphere might be used to predict the clinical-outcome, hence, emerging as critical recovery parameters to be considered and evaluated in future with a larger data-samples. These might be the plasticity markers predicting the responsiveness of chronic post-stroke patients (41).

\subsection{Changes due to the device}

The exoskeleton training in RG induced an evident modulation in ipsilesional and contralesional-hemispheres. However, changes in CG were found to be limited only to the clinical-scales, and in addition, the changes in neurophysiological parameters were specifically found in the RG. The decrease of RMT and change in RMT asymmetry from distal-muscle was also accompanied by functional markers-FMW/H evidencing sensorimotor-plasticity, functional recovery with task-dependent rehabilitation. Multiple strategies used during intervention to encourage clinically relevant neuroplasticity were to use movement goals that are specific, measurable, achievable, repetitive, and timed (70). It was also supported with maximizing voluntary residual muscle activity (using EMG thresholds) with real-time extrinsic visual performance biofeedback and intrinsic proprioceptive feedback for sensorimotor integration in every cycle of movement as synergy based training approach for maximizing brain reorganization (71)(72).

Since RG and CG had very similar lesion locations and size with all patients having their motor paths affected, indicating increase in cortical excitability might be attributed to the different interventions in the groups. There was a limited number of cases in individual subgroups, i.e. only 2/12 patients from the RG and 2/11 patients from the CG belonged to the subacute stage ( 3 months -6 months), the majority of patients are chronic. The CG included 5 subcortical and 6 cortical stroke. The RG included 6 subcortical and 6 cortical stroke. Considering threshold for recovery as MCID for FMU/L 6.6 (32)(33), out of 11 patients in CG, total 7 patients (5 subcortical and 2 cortical) exceeded the threshold and all 
twelve patients in RG exceeded the threshold. Any conclusion on the trend for sub-acute or chronic stroke and the responders or the nonresponders to the intervention would be highly presumptive and misleading because of the small sample size. The outcomes provided critical data to plan a multicentric trial with large sample size in the future to systematically investigate the potential of the exoskeleton.

\subsection{Limitations and Future Work}

Even though the data are promising, the study had few limitations such as small sample size and lack of an activity level measurement like Wolf Motor Function test and Action Research Arm Test, goal-directed or translation-to-home-use measurements, no midterm clinical assessment, and long term follow-up of patients. As most of the patients at our quaternary hospital came from far places across India and it was not possible to follow-up with them once they have left the city. Another limitation was therapist performing both sets of interventions could not be blinded to the group allocation. There are several ways the study can be improved. The sample size can be increased and patient groups can be further subdivided into sub-acute and chronic stages to evaluate any difference in rehabilitation outcomes, with mid-term clinical assessment and long-term follow-up with the double-blinded protocol. Different distal goal-directed and translation to home measures could be included like WMFT or ARAT, Functional Independence Measure, Canadian Occupational Performance Measure or Motor Activity Log, nine-hole pegboard, stroke Impact scale, Interhemispheric Inhibition measures using TMS, etc. The device currently is in the prototype stage with clinical validation, thus the BIOPAC EMG system was used in data acquisition for research and validation. In the future, this will be easily replaced by an MYOWARE or an in-house build EMG amplifier. The device will have an LCD touch screen for settings and feedback. These features will make the system more aesthetic, compact, and accessible. Once the device is optimized in terms of weight, aesthetics and compactness, it can be deployed for home-based rehabilitation in the future. Also, with a minor modification, the device can synchronize wrist extension with finger extension which can be further explored for outcome in patients with stroke.

\section{Conclusion}

The results observed in the study, an improvement in clinical scales, and increased cortical-excitability in patients with stroke, suggest that robotic-therapy might have implications for facilitating the recovery of stroke neuro-rehabilitation.

\section{Declarations}

Funding: Science and Engineering Research Board, Department of Science and Technology, India

Ethical Statement: Institutional Review Board (IRB) at All India Institute of Medical Sciences (AlIMS), New-Delhi, India, approved the study under protocol-number IEC/NP-99/13.03.2015. All the patients signed the written informed consent before enrolment.

Consent for Publication: All the patients signed the written informed consent for publication before enrolment.

Availability of Data and Material: The datasets used and/or analyzed in the current study are available from the corresponding author on reasonable request.

Competing Interest: The Author(s) declare(s) that there is no conflict of interest.

Funding: This work was financially supported by SERB, DST India (YSS/2015/000697).

Authors Contributors: NS and AM conceptualized and designed the study. AM led the study and provided the scientific inputs. MS performed patient recruitment, physiotherapy, robotic therapy and data collection. NK and PS provided the scientific inputs, clinical support, and clinical resources for experiments. NS performed a literature survey, developed a device, data analysis, data interpretation, wrote the manuscript. AM reviewed the manuscript at multiple iterations with NS. All authors reviewed and approved the manuscript.

Acknowledgment: The authors thank all patients who participated in the study. The authors also thank Dr. Esha Baidya and Devashish for their help in the calculation of the volume of the lesion in patients.

\section{References}

1. Stroke Statistics | Internet Stroke Center [Internet]. [cited 2019 Aug 25]. Available from: http://www.strokecenter.org/patients/aboutstroke/stroke-statistics/

2. Kuo C-L, Hu G-C. Post-stroke Spasticity: A Review of Epidemiology, Pathophysiology, and Treatments. Int J Gerontol [Internet]. 2018 Dec 1 [cited 2019 Aug 23];12(4):280-4. Available from: https://www.sciencedirect.com/science/article/pii/S1873959818300073 
3. Wolf SL, Winstein CJ, Miller JP, Taub E, Uswatte G, Morris D, et al. Effect of constraint-induced movement therapy on upper extremity function 3 to 9 months after stroke: The EXCITE randomized clinical trial. J Am Med Assoc [Internet]. 2006 Nov 1 [cited 2020 Jun 22];296(17):2095-104. Available from: https://pubmed.ncbi.nlm.nih.gov/17077374/

4. Yarossi M, Patel J, Qiu Q, Massood S, Fluet G, Merians A, et al. The Association Between Reorganization of Bilateral M1 Topography and Function in Response to Early Intensive Hand Focused Upper Limb Rehabilitation Following Stroke Is Dependent on Ipsilesional Corticospinal Tract Integrity. Front Neurol [Internet]. 2019 [cited 2019 Aug 22];10:258. Available from: http://www.ncbi.nlm.nih.gov/pubmed/30972004

5. Qian Q, Hu X, Lai Q, Ng SC, Zheng Y, Poon W. Early stroke rehabilitation of the upper limb assisted with an electromyography-driven neuromuscular electrical stimulation-robotic arm. Front Neurol. 2017;8(SEP):1-13.

6. Linder SM, Rosenfeldt AB, Reiss A, Buchanan S, Sahu K, Bay CR, et al. The home stroke rehabilitation and monitoring system trial: A randomized controlled trial. Int J Stroke. 2013;8(1):46-53.

7. Hu XL, Tong KY, Wei XJ, Rong W, Susanto EA, Ho SK. The effects of post-stroke upper-limb training with an electromyography (EMG)driven hand robot. J Electromyogr Kinesiol. 2013;23(5):1065-74.

8. Hu XL, Tong KY, Song R, Zheng XJ, Leung WWF. A comparison between electromyography-driven robot and passive motion device on wrist rehabilitation for chronic stroke. Neurorehabil Neural Repair. 2009;23(8):837-46.

9. Hu XL, Tong KY, Li R, Xue JJ, Ho SK, Chen P. The effects of electromechanical wrist robot assistive system with neuromuscular electrical stimulation for stroke rehabilitation. J Electromyogr Kinesiol [Internet]. 2012 Jun [cited 2018 Sep 6];22(3):431-9. Available from: http://www.ncbi.nlm.nih.gov/pubmed/22277205

10. Takahashi CD, Der-y ÃL, Le V, Motiwala RR, Cramer SC. Robot-based hand motor therapy after stroke. 2008;

11. Hu XL, Tong KY, Song R, Zheng XJ, Lui KH, Leung WWF, et al. Quantitative evaluation of motor functional recovery process in chronic stroke patients during robot-assisted wrist training. J Electromyogr Kinesiol [Internet]. 2009;19(4):639-50. Available from: http://dx.doi.org/10.1016/j.jelekin.2008.04.002

12. Song R, Tong KY, Hu X, Zhou W. Myoelectrically controlled wrist robot for stroke rehabilitation. J Neuroeng Rehabil. 2013;10(1):1-8.

13. Hu XL, Tong RKY, Ho NSK, Xue JJ, Rong W, Li LSW. Wrist Rehabilitation Assisted by an Electromyography-Driven Neuromuscular Electrical Stimulation Robot after Stroke. Neurorehabil Neural Repair. 2015;29(8):767-76.

14. Rong W, Li W, Pang M, Hu J, Wei X, Yang B, et al. A Neuromuscular Electrical Stimulation (NMES) and robot hybrid system for multi-joint coordinated upper limb rehabilitation after stroke. J Neuroeng Rehabil. 2017;14(1):1-13.

15. Nam C, Rong W, Li W, Xie Y, Hu X, Zheng Y. The effects of upper-limb training assisted with an electromyography-driven neuromuscular electrical stimulation robotic hand on chronic stroke. Front Neurol. 2017;8(DEC).

16. Oujamaa L, Relave I, Froger J, Mottet D, Pelissier J-Y. Rehabilitation of arm function after stroke. Literature review. Ann Phys Rehabil Med [Internet]. 2009 Apr [cited 2017 Oct 8];52(3):269-93. Available from: http://www.ncbi.nlm.nih.gov/pubmed/19398398

17. Balasubramanian S, Klein J, Burdet E. Robot-assisted rehabilitation of hand function. Curr Opin Neurol [Internet]. 2010 Dec [cited 2019 May 22];23(6):661-70. Available from: https://insights.ovid.com/crossref?an=00019052-201012000-00019

18. Lee M, Rittenhouse M, Abdullah HA. Design Issues for Therapeutic Robot Systems: Results from a Survey of Physiotherapists. J Intell Robot Syst [Internet]. 2005 Mar [cited 2019 Aug 28];42(3):239-52. Available from: http://link.springer.com/10.1007/s10846-004-7194-y

19. Singh N, Saini M, Anand S, Kumar N, Srivastava MVP, Mehndiratta A. Robotic Exoskeleton for Wrist and Fingers Joint in Post-Stroke Neuro-Rehabilitation for Low-Resource Settings. IEEE Trans Neural Syst Rehabil Eng [Internet]. 2019 [cited 2019 Sep 27];1-1. Available from: https://ieeexplore.ieee.org/document/8846101/

20. Awiszus F. Chapter 2 TMS and threshold hunting. Suppl Clin Neurophysiol [Internet]. 2003 Jan 1 [cited 2019 Jul 10];56:13-23. Available from: https://www.sciencedirect.com/science/article/abs/pii/S1567424X09702053

21. Singh N, Saini M, Kumar N, Deepak KK, Anand S, Srivastava MVP, et al. Time-Frequency Analysis of Motor-Evoked Potential in Patients with Stroke vs Healthy Subjects: a Transcranial Magnetic Stimulation Study. SN Compr Clin Med. 2019 Oct;1(10):764-80.

22. Chen R, Cros D, Curra A, Di Lazzaro V, Lefaucheur JP, Magistris MR, et al. The clinical diagnostic utility of transcranial magnetic stimulation: Report of an IFCN committee. Clin Neurophysiol. 2008;119(3):504-32.

23. Stinear CM, Barber PA, Smale PR, Coxon JP, Fleming MK, Byblow WD. Functional potential in chronic stroke patients depends on corticospinal tract integrity. Brain [Internet]. 2006 Nov 21 [cited 2019 May 12];130(1):170-80. Available from: http://www.ncbi.nlm.nih.gov/pubmed/17148468

24. Kim G-W, Won YH, Park S-H, Seo J-H, Ko M-H. Can Motor Evoked Potentials Be an Objective Parameter to Assess Extremity Function at the Acute or Subacute Stroke Stage? Ann Rehabil Med [Internet]. 2015 Apr [cited 2019 Aug 19];39(2):253. Available from: http://www.ncbi.nlm.nih.gov/pubmed/25932422 
25. Amengual JL, Valero-Cabré A, de las Heras MV, Rojo N, Froudist-Walsh S, Ripollés P, et al. Prognostic value of cortically induced motor evoked activity by TMS in chronic stroke: Caveats from a revealing single clinical case. BMC Neurol [Internet]. 2012 Dec 8 [cited 2019 Aug 19];12(1):35. Available from: http://bmcneurol.biomedcentral.com/articles/10.1186/1471-2377-12-35

26. Takeuchi N, Tada T, Toshima M, Ikoma K. Correlation of motor function with transcallosal and intracortical inhibition after stroke. J Rehabil Med [Internet]. 2010 [cited 2019 Aug 20];42(10):962-6. Available from: https://medicaljournals.se/jrm/content/abstract/10.2340/16501977-0628

27. Koski L, Mernar TJ, Dobkin BH. Immediate and Long-Term Changes in Corticomotor Output in Response to Rehabilitation: Correlation with Functional Improvements in Chronic Stroke. Neurorehabil Neural Repair [Internet]. 2004 Dec 1 [cited 2019 Sep 1];18(4):230-49. Available from: http://journals.sagepub.com/doi/10.1177/1545968304269210

28. Huynh W, Vucic S, Krishnan A V., Lin CSY, Kiernan MC. Exploring the evolution of cortical excitability following acute stroke. Neurorehabil Neural Repair. 2016 Mar 1;30(3):244-57.

29. Plantin J, Pennati G V., Roca P, Baron JC, Laurencikas E, Weber K, et al. Quantitative assessment of hand spasticity after stroke: Imaging correlates and impact on motor recovery. Front Neurol. 2019;10(JUL).

30. Lundquist CB, Maribo T. The Fugl-Meyer assessment of the upper extremity: reliability, responsiveness and validity of the Danish version. Disabil Rehabil [Internet]. 2017 Apr 24 [cited 2019 Sep 8];39(9):934-9. Available from: http://www.ncbi.nlm.nih.gov/pubmed/27062881

31. Takahashi CD, Der-Yeghiaian L, Le V, Motiwala RR, Cramer SC. Robot-based hand motor therapy after stroke. Brain. 2008;131(2):425-37.

32. Gladstone DJ, Danells CJ, Black SE, Article R. The Fugl-Meyer Assessment of Motor Recovery after Stroke: A Critical Review of Its Measurement Properties. 2002.

33. Shin J-H, Kim M-Y, Lee J-Y, Jeon Y-J, Kim S, Lee S, et al. Effects of virtual reality-based rehabilitation on distal upper extremity function and health-related quality of life: a single-blinded, randomized controlled trial. J Neuroeng Rehabil [Internet]. 2016;13(1):17. Available from: http://www.jneuroengrehab.com/content/13/1/17

34. Kuthiala N. International Journal of Neurorehabilitation rTMS and CIMT for Neurofunctional Recovery in Chronic Stroke. 2020;

35. McIntyre A, Viana R, Janzen S, Mehta S, Pereira S, Teasell R. Systematic review and meta-analysis of constraint-induced movement therapy in the hemiparetic upper extremity more than six months post stroke [Internet]. Vol. 19, Topics in Stroke Rehabilitation. Top Stroke Rehabil; 2012 [cited 2021 Jan 11]. p. 499-513. Available from: https://pubmed.ncbi.nlm.nih.gov/23192715/

36. Wittenberg GF, Chen R, Ishii K, Bushara KO, Taub E, Gerber LH, et al. Constraint-induced therapy in stroke: Magnetic-stimulation motor maps and cerebral activation. Neurorehabil Neural Repair [Internet]. 2003 Mar 1 [cited 2021 Jan 12];17(1):48-57. Available from: https://pubmed.ncbi.nlm.nih.gov/12645445/

37. Sawaki L, Butler AJ, Leng X, Wassenaar PA, Mohammad YM, Blanton S, et al. Constraint-induced movement therapy results in increased motor map area in subjects 3 to 9 months after stroke. Neurorehabil Neural Repair. 2008 Sep;22(5):505-13.

38. Doan-Aslan M, Nakipolu-Yüzer GF, Doan A, Karabay I, Özgirgin N. The effect of electromyographic biofeedback treatment in improving upper extremity functioning of patients with hemiplegic stroke. J Stroke Cerebrovasc Dis [Internet]. 2012 Apr [cited 2021 Jan 12];21(3):187-92. Available from: https://pubmed.ncbi.nlm.nih.gov/20880720/

39. Zheng CJ, Liao WJ, Xia WG. Effect of combined low-frequency repetitive transcranial magnetic stimulation and virtual reality training on upper limb function in subacute stroke: A double-blind randomized controlled trail. J Huazhong Univ Sci Technol - Med Sci [Internet]. 2015 [cited 2021 Jan 12];35(2):248-54. Available from: https://pubmed.ncbi.nlm.nih.gov/25877360/

40. Krishnan C, Ranganathan R, Kantak SS, Dhaher YY, Rymer WZ. Active robotic training improves locomotor function in a stroke survivor. J Neuroeng Rehabil [Internet]. 2012;9:57. Available from: http://www.pubmedcentral.nih.gov/articlerender.fcgi? artid=3480863\&tool=pmcentrez\&rendertype=abstract

41. Calabrò RS, Russo M, Naro A, Milardi D, Balletta T, Leo A, et al. Who May Benefit From Armeo Power Treatment? A Neurophysiological Approach to Predict Neurorehabilitation Outcomes. PM R. 2016 Oct 1;8(10):971-8.

42. Calabrò RS, Naro A, Leo A, Bramanti P. Usefulness of robotic gait training plus neuromodulation in chronic spinal cord injury: a case report. J Spinal Cord Med [Internet]. 2017 Jan 2 [cited 2019 Aug 20];40(1):118-21. Available from: https://www.tandfonline.com/doi/full/10.1080/10790268.2016.1153275

43. Kang Y, Park H, Kim H, Lim T, Ku J, Cho S, et al. Upper extremity rehabilitation of stroke: Facilitation of corticospinal excitability using virtual mirror paradigm. J Neuroeng Rehabil [Internet]. 2012 [cited 2019 Aug 20];9(1):71. Available from: http://jneuroengrehab.biomedcentral.com/articles/10.1186/1743-0003-9-71

44. Hendricks HT, Zwarts MJ, Plat EF, Van Limbeek J. Systematic review for the early prediction of motor and functional outcome after stroke by using motor-evoked potentials. Arch Phys Med Rehabil [Internet]. 2002 [cited 2021 Jan 7];83(9):1303-8. Available from: https://pubmed.ncbi.nlm.nih.gov/12235613/ 
45. Hendricks HT, Pasman JW, Van Limbeek J, Zwarts MJ. Motor evoked potentials of the lower extremity in predicting motor recovery and ambulation after stroke: A cohort study. Arch Phys Med Rehabil. 2003 Sep 1;84(9):1373-9.

46. Lim JY, Oh M-K, Park J, Paik N-J. Does Measurement of Corticospinal Tract Involvement Add Value to Clinical Behavioral Biomarkers in Predicting Motor Recovery after Stroke? Neural Plast [Internet]. 2020 Nov 27 [cited 2021 Jan 7];2020:1-10. Available from: https://pubmed.ncbi.nlm.nih.gov/33354207/

47. Escudero J V, Sancho J, Bautista D, Escudero M, López-Trigo J. Prognostic value of motor evoked potential obtained by transcranial magnetic brain stimulation in motor function recovery in patients with acute ischemic stroke. Stroke. 1998;29(9):1854-9.

48. Talelli P, Greenwood RJ, Rothwell JC. Arm function after stroke: Neurophysiological correlates and recovery mechanisms assessed by transcranial magnetic stimulation. Clin Neurophysiol [Internet]. 2006 Aug 1 [cited 2019 May 12];117(8):1641-59. Available from: https://www.sciencedirect.com/science/article/pii/S1388245706000484?via\%3Dihub

49. Edwardson MA, Lucas TH, Carey JR, Fetz EE. New modalities of brain stimulation for stroke rehabilitation. Exp Brain Res. 2013;224(3):335-58.

50. Dodd KC, Nair VA, Prabhakaran V. Role of the contralesional vs. Ipsilesional hemisphere in stroke recovery. Vol. 11, Frontiers in Human Neuroscience. Frontiers Media S. A; 2017. p. 469-469.

51. Du J, Yang F, Hu J, Hu J, Xu Q, Cong N, et al. Effects of high- and low-frequency repetitive transcranial magnetic stimulation on motor recovery in early stroke patients: Evidence from a randomized controlled trial with clinical, neurophysiological and functional imaging assessments. Neurolmage Clin [Internet]. 2019 [cited 2019 Sep 27];21:101620. Available from: http://www.ncbi.nlm.nih.gov/pubmed/30527907

52. Liao WW, Wu CY, Hsieh YW, Lin KC, Chang WY. Effects of robot-assisted upper limb rehabilitation on daily function and real-world arm activity in patients with chronic stroke: A randomized controlled trial. Clin Rehabil. 2012;26(2):111-20.

53. Lee M-J, Lee J-H, Lee S-M. Effects of robot-assisted therapy on upper extremity function and activities of daily living in hemiplegic patients: A single-blinded, randomized, controlled trial. Technol Heal Care [Internet]. 2018;1:1-8. Available from: http://www.ncbi.nlm.nih.gov/pubmed/30124459\%0Ahttp://www.medra.org/servlet/aliasResolver?alias=iospress\&doi=10.3233/THC181336

54. Lambercy O, Dovat L, Yun H, Wee SK, Kuah CW, Chua KS, et al. Effects of a robot-assisted training of grasp and pronation/supination in chronic stroke: A pilot study. J Neuroeng Rehabil. 2011;8(1).

55. Colombo R, Pisano F, Mazzone A, Delconte C, Micera S, Carrozza MC, et al. Design strategies to improve patient motivation during robotaided rehabilitation. J Neuroeng Rehabil [Internet]. 2007 [cited 2017 Oct 8];4(1):3. Available from: http://jneuroengrehab.biomedcentral.com/articles/10.1186/1743-0003-4-3

56. Duret C, Courtial O, Grosmaire AG, Hutin E. Use of a robotic device for the rehabilitation of severe upper limb paresis in subacute stroke: Exploration of patient/robot interactions and the motor recovery process. Biomed Res Int. 2015;2015.

57. Calabrò RS, Naro A, Russo M, Bramanti P, Carioti L, Balletta T, et al. Shaping neuroplasticity by using powered exoskeletons in patients with stroke: a randomized clinical trial. J Neuroeng Rehabil [Internet]. 2018 Apr 25 [cited 2020 Jun 22];15(1):35. Available from: https://jneuroengrehab.biomedcentral.com/articles/10.1186/s12984-018-0377-8

58. Kubis N. Non-Invasive Brain Stimulation to Enhance Post-Stroke Recovery. Front Neural Circuits [Internet]. 2016 [cited 2017 Dec 27];10:56. Available from: http://www.ncbi.nlm.nih.gov/pubmed/27512367

59. Solomons C, Shanmugasundaram V. A review of transcranial electrical stimulation methods in stroke rehabilitation. Neurol India [Internet]. 2019 [cited 2019 Aug 19];67(2):417. Available from: http://www.ncbi.nlm.nih.gov/pubmed/31085852

60. Henderson L, Paul M, David M, Deana G, Davalos B. THESIS THE USE OF REPETITIVE TRANSCRANIAL MAGNETIC STIMULATION AS AN ADJUNCT TO CONSTRAINT INDUCED THERAPY Submitted By [Internet]. 2013 [cited 2019 Aug 20]. Available from: https://mountainscholar.org/bitstream/handle/10217/81026/Henderson_colostate_0053N_12150.pdf?sequence=1

61. Kim J, Yim J. Effects of High-Frequency Repetitive Transcranial Magnetic Stimulation Combined with Task-Oriented Mirror Therapy Training on Hand Rehabilitation of Acute Stroke Patients. Med Sci Monit [Internet]. 2018 Feb 6 [cited 2019 Aug 20];24:743-50. Available from: http://www.ncbi.nlm.nih.gov/pubmed/29402879

62. Calabrò RS, Naro A, Leo A, Bramanti P. Usefulness of robotic gait training plus neuromodulation in chronic spinal cord injury: a case report. J Spinal Cord Med [Internet]. 2017 Jan 2 [cited 2019 Aug 20];40(1):118-21. Available from: http://www.ncbi.nlm.nih.gov/pubmed/27077568

63. Kang Y, Park H, Kim H, Lim T, Ku J, Cho S, et al. Upper extremity rehabilitation of stroke: Facilitation of corticospinal excitability using virtual mirror paradigm. J Neuroeng Rehabil [Internet]. 2012 Oct 4 [cited 2019 Aug 20];9(1):71. Available from: http://www.ncbi.nlm.nih.gov/pubmed/23035951 
64. Edwards DJ, Krebs HI, Rykman A, Zipse J, Thickbroom GW, Mastaglia FL, et al. Raised corticomotor excitability of M1 forearm area following anodal tDCS is sustained during robotic wrist therapy in chronic stroke. Restor Neurol Neurosci [Internet]. 2009 [cited 2019 Aug 20];27(3):199-207. Available from: http://www.ncbi.nlm.nih.gov/pubmed/19531875

65. Giacobbe V, Krebs HI, Volpe BT, Pascual-Leone A, Rykman A, Zeiarati G, et al. Transcranial direct current stimulation (tDCS) and robotic practice in chronic stroke: the dimension of timing. NeuroRehabilitation [Internet]. 2013 [cited 2019 Aug 20];33(1):49-56. Available from: http://www.ncbi.nlm.nih.gov/pubmed/23949028

66. Patel J, Fluet G, Qiu Q, Yarossi M, Merians A, Tunik E, et al. Intensive virtual reality and robotic based upper limb training compared to usual care, and associated cortical reorganization, in the acute and early sub-acute periods post-stroke: a feasibility study. J Neuroeng Rehabil [Internet]. 2019 Dec 17 [cited 2019 Aug 20];16(1):92. Available from: https://jneuroengrehab.biomedcentral.com/articles/10.1186/s12984-019-0563-3

67. Du J, Hu J, Hu J, Xu Q, Zhang Q, Liu L, et al. Aberrances of cortex excitability and connectivity underlying motor deficit in acute stroke. Neural Plast [Internet]. 2018 [cited 2021 Jan 10];2018. Available from: https://pubmed.ncbi.nlm.nih.gov/30420876/

68. Liepert J, Bauder H, Miltner WHR, Taub E, Weiller C. Treatment-Induced Cortical Reorganization After Stroke in Humans. Stroke [Internet]. 2000 Jun [cited 2019 Sep 1];31(6):1210-6. Available from: https://www.ahajournals.org/doi/10.1161/01.STR.31.6.1210

69. Traversa R, Cicinelli P, Pasqualetti P, Filippi M, Rossini PM. Follow-up of interhemispheric differences of motor evoked potentials from the "affected" and "unaffected" hemispheres in human stroke. Brain Res [Internet]. 1998 Aug 24 [cited 2020 Jul 20];803(1-2):1-8. Available from: https://pubmed.ncbi.nlm.nih.gov/9729235/

70. Scobbie L, McLean D, Dixon D, Duncan E, Wyke S. Implementing a framework for goal setting in community based stroke rehabilitation: A process evaluation. BMC Health Serv Res. 2013;13(1).

71. Volpe BT, Ferraro M, Lynch D, Christos P, Krol J, Trudell C, et al. Robotics and other devices in the treatment of patients recovering from stroke. Curr Atheroscler Rep [Internet]. 2004 Jul [cited 2019 Aug 26];6(4):314-9. Available from:

http://www.ncbi.nlm.nih.gov/pubmed/15191707

72. Cho KH, Hong M-R, Song W-K. Upper limb robotic rehabilitation for chronic stroke survivors: a single-group preliminary study. J Phys Ther Sci [Internet]. 2018 Apr [cited 2019 Aug 26];30(4):580-3. Available from: http://www.ncbi.nlm.nih.gov/pubmed/29706710

\section{Figures}

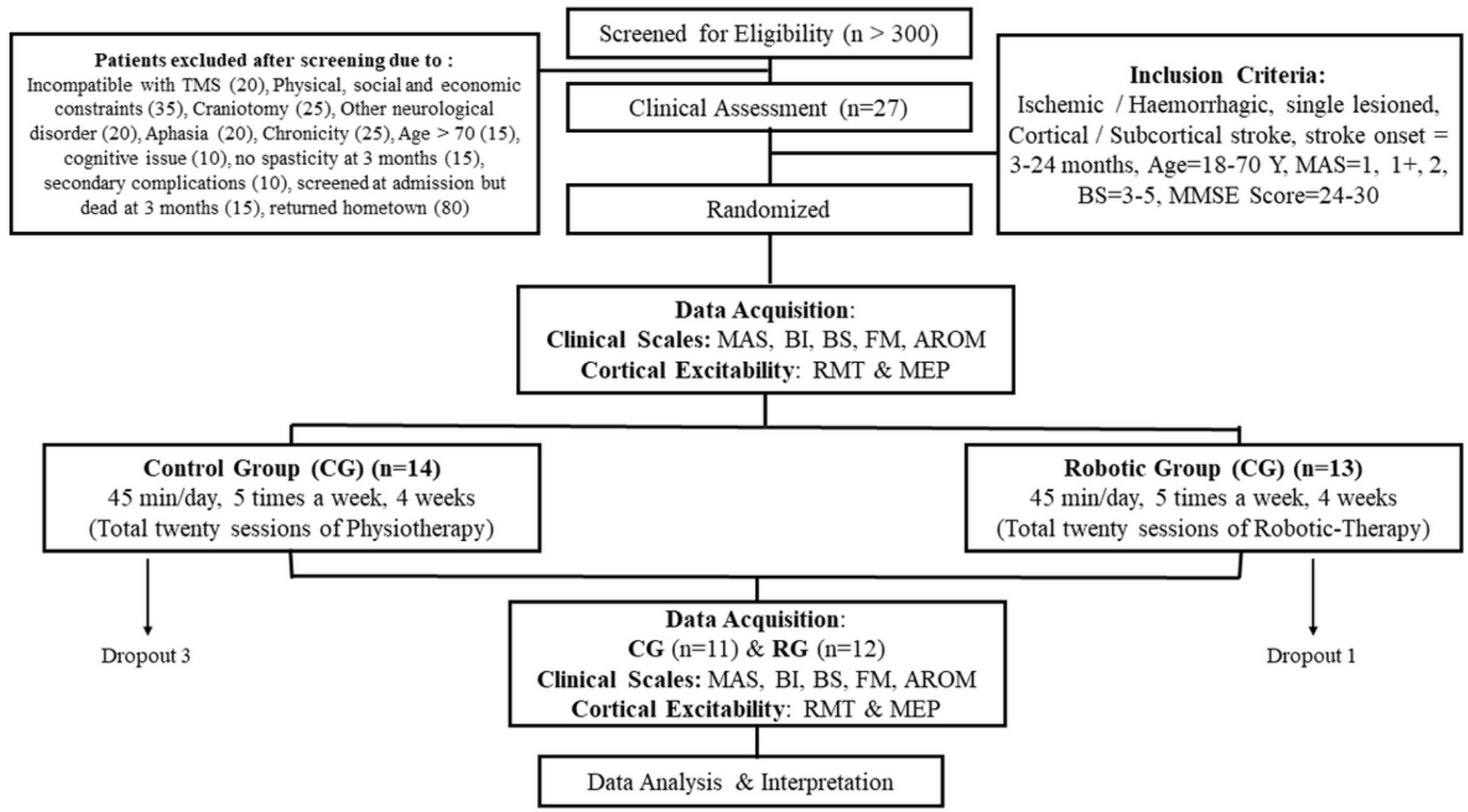

Figure 1 


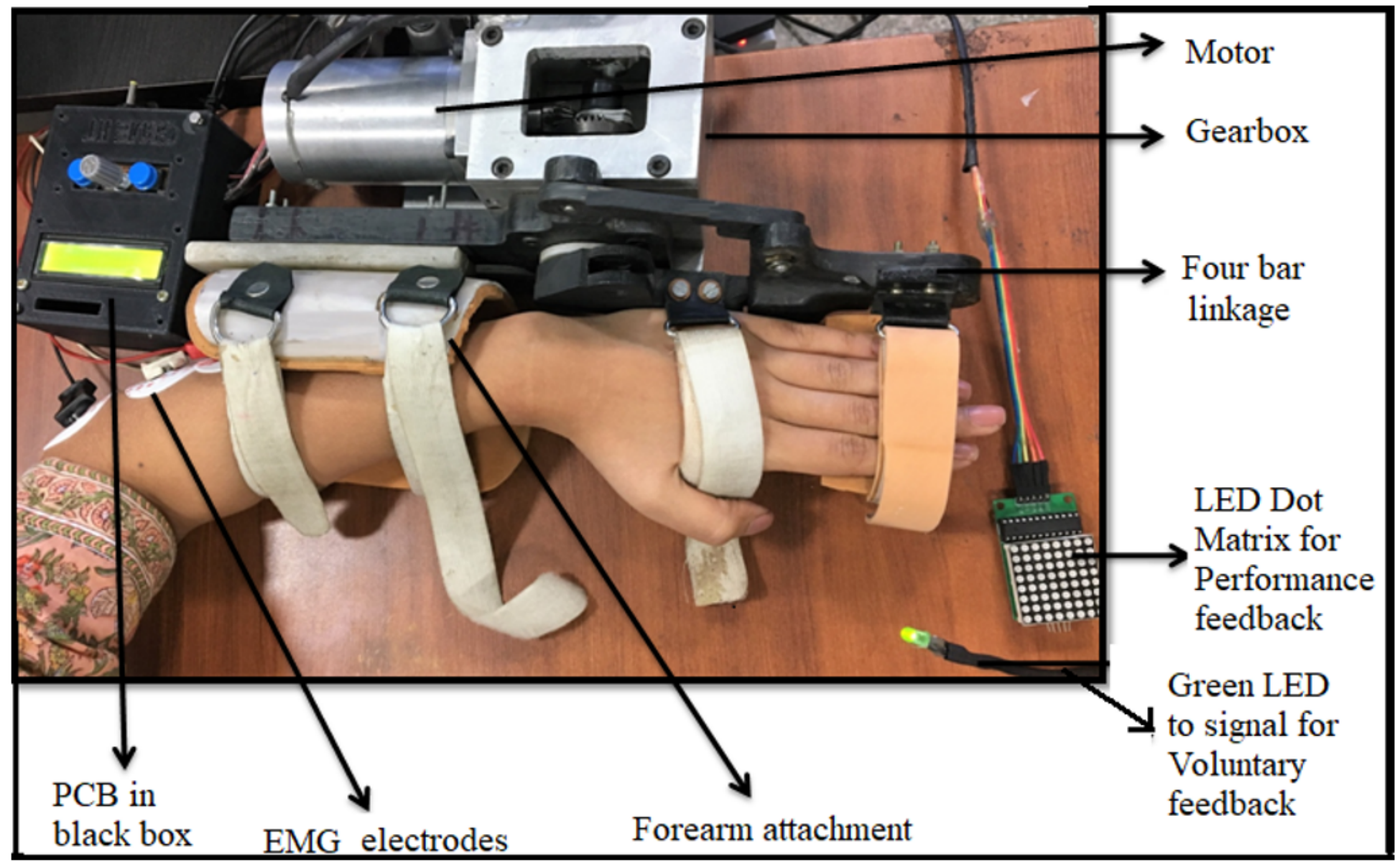

Figure 2

Whole set-up of exoskeleton with performance biofeedback, voluntary cue, and PCB in the black control-box which also works as userinterface (19)
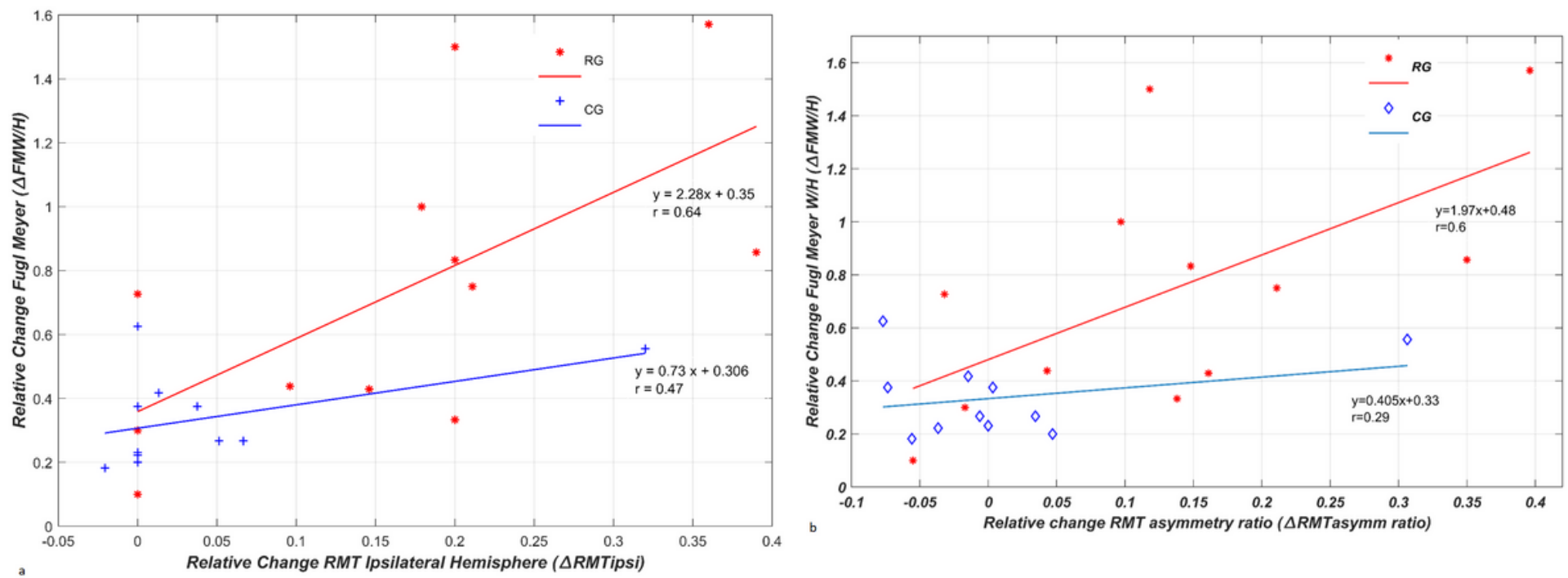

Figure 3

a: Scatter-plot showing the relationship between improvements in RMT in the ipsilesional-hemisphere and improvements in functional performance of the distal-component pre-to-post-therapy for individual patient's data. Greater decreases in motor-threshold tend to show greater increases in FMW/H. Red Line (RG) and the blue line (CG) represents a linear-trend in improvement in distal motor-outcome ( $\Delta \mathrm{FMW} / \mathrm{H})$ score as a function of change in the ipsilesional-hemisphere ( $\triangle$ RMTipsi) in RG and CG pre-to-post-therapy in which RG shows a significant 
correlation $(r=0.64, F=7.24, p=0.022) b$ : Scatter-plot showing the relationship between change in RMT asymmetry-ratio (ipsilesional/contralesional) pre to post-therapy and functional performance of distal component for individual patient's data. Greater decreases in motor threshold tend to show greater increases in FMW/H. The Red line (RG) and the blue line (CG) represents a linear-trend in improvement in distal motor-outcome $(\Delta \mathrm{FMW} / \mathrm{H})$ score as a function of change in RMT-ratio $(\Delta \mathrm{RMTasymm}$-ratio) in RG and CG pre to posttherapy in which $R G$ shows a significant correlation $(r=0.6, F=5.77, p=0.03)$

\section{Supplementary Files}

This is a list of supplementary files associated with this preprint. Click to download.

- Supplementrymaterial.docx

- cONSORTchecklist.docx 